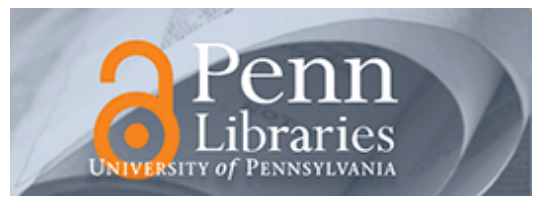

University of Pennsylvania

ScholarlyCommons

$12-2010$

\title{
Exit Rights and Entrance Paths: Accommodating Cultural Diversity in a Liberal Democracy
}

Sigal R. Ben-Porath

University of Pennsylvania, sigalbp@gse.upenn.edu

Follow this and additional works at: https://repository.upenn.edu/gse_pubs

\section{Recommended Citation}

Ben-Porath, S. R. (2010). Exit Rights and Entrance Paths: Accommodating Cultural Diversity in a Liberal Democracy. Retrieved from https://repository.upenn.edu/gse_pubs/232

Suggested Citation:

Ben-Porath, S. (2010). Exit Rights and Entrance Paths: Accommodating Cultural Diversity in a Liberal Democracy. Perspectives on Politics. Vol. 8(4). pp. 1021-1033.

Journal homepage: http://journals.cambridge.org/action/displayJournal?jid=PPS

This paper is posted at ScholarlyCommons. https://repository.upenn.edu/gse_pubs/232

For more information, please contact repository@pobox.upenn.edu. 


\title{
Exit Rights and Entrance Paths: Accommodating Cultural Diversity in a Liberal Democracy
}

\author{
Abstract \\ The debate over the accommodation of culture in liberal democracies tends to emphasize exit rights. \\ Autonomy is typically taken as a pre-condition for exit, and public schools are often charged with \\ promoting or facilitating it. I argue that diversity liberals have a more justifiable viewthan that of autonomy \\ liberals on cultural accommodation, but diversity liberalism too should reframe its view of exit rights. \\ Narrow exit rights that protect basic human rights should be maintained and augmented with entrance \\ paths into general society. I further suggest that for exit rights along with entrance paths to provide the \\ morally required conditions for accommodating culture while respecting freedom, policies in this realm \\ should be designed to address adults rather than children. I consider the effect of this dual change of \\ perspective on the accommodation of culture in democratic institutions, including schools.

\section{Comments} \\ Suggested Citation: \\ Ben-Porath, S. (2010). Exit Rights and Entrance Paths: Accommodating Cultural Diversity in a Liberal \\ Democracy. Perspectives on Politics. Vol. 8(4). pp. 1021-1033. \\ Journal homepage: http://journals.cambridge.org/action/displayJournal?jid=PPS
}




\title{
Exit Rights and Entrance Paths: Accommodating Cultural Diversity in a Liberal Democracy
}

\author{
Sigal Ben-Porath
}

\begin{abstract}
The debate over the accommodation of culture in liberal democracies tends to emphasize exit rights. Autonomy is typically taken as a pre-condition for exit, and public schools are often charged with promoting or facilitating it. I argue that diversity liberals have a more justifiable view than that of autonomy liberals on cultural accommodation, but diversity liberalism too should reframe its view of exit rights. Narrow exit rights that protect basic human rights should be maintained and augmented with entrance paths into general society. I further suggest that for exit rights along with entrance paths to provide the morally required conditions for accommodating culture while respecting freedom, policies in this realm should be designed to address adults rather than children. I consider the effect of this dual change of perspective on the accommodation of culture in democratic institutions, including schools.
\end{abstract}

$T$ he tension between the accommodation of comprehensive communities on the one hand, and the enforcement of exit rights to protect individuals within these communities on the other, is an ongoing challenge in liberal democracies. I aim to relieve some of this tension by suggesting that liberal democracies should focus more attention on providing individual members of comprehensive communities with entrance paths into other parts of society rather than intervening in these communities to protect a robust form of exit rights. Entrance paths can be supported by policies that aim to reduce the cost of entry into dominant society by providing opportunities for exiting members of comprehensive communities to engage in work, leisure, and civic life. Only by sustained attention to and support for such paths can liberal democracies truly accommodate cultural diversity in ways consistent with liberal pluralism.

Consider the Fundamentalist Church of Jesus Christ of Latter-Day Saints (FLDS), a comprehensive community whose values and practices are clearly distinct from those of dominant American society. In recent years, the American public has learned of two separate cases of exit from

Sigal Ben-Porath is Assistant Professor at the Graduate School of Education and special assistant to the president at the University of Pennsylvania (sigalbp@gse.upenn.edu).

Her most recent book is Tough Choices: Structured Paternalism and the Landscape of Choice, Princeton University Press (2010). The author is grateful to the Dewey Seminar participants, Eamonn Callan, Jeff Isaac and Jeff Spinner-Halev for comments on earlier drafts. this sect. First was the depiction of "lost boys"-young men who left the sect, some voluntarily, others sent off by the leader, Warren Jeffs, whose professed support of polygamy necessitated having fewer young men than young women in the sect's compound. ${ }^{1}$ Later, the sect was again in the news with the dramatic images of law enforcement officials removing 439 children and young women from the sect's Yearning for Zion ranch in Texas following allegations of forced underage marriage, child abuse, and rape by Jeffs and several male members. ${ }^{2}$

The removal of this large group of youngsters from the compound and supposedly away from the influence of the sect's leader seems to offer a mass exit opportunity for some of the sect's vulnerable members. The intervention by authorities, aimed at protecting these young women and children from an apparent violation of their rights, clashed in some cases with the women's expressed preferences (uninformed as they might be), and illustrated the ever-present tension between the protection of individual freedoms and rights and the accommodation of culture. Both the right to exit one's cultural group and the commitment of dominant liberal-democratic society to enable such exit are key aspects of democratic theory today. ${ }^{3}$ Liberal theorists, including those committed to cultural rights, view cultural groups with suspicion as they consider granting them group rights, intervening in their practices, or protecting their vulnerable members. Many liberal theories are concerned with proposing ways to curb the harmful effects of culture on individual flourishing or political equality. The social realm that liberal theorists tend to envision is one in which there is a dominant society governed by principles of autonomy, individuality and rationality, within which enclaves of 
comprehensive groups endorse practices that compromise some of the core principles of this mainstream society. For this line of liberal thinking, one major challenge is finding a suitable response to individuals within these subgroups, some of whom may be perfectly content with their condition (albeit not necessarily in a reflective way) while others may be oppressed or wish to leave for other reasons. Most liberal responses to the challenge presented by illiberal cultures share a common feature: a focus on support for exit rights. As Susan Moller Okin put it, "Any consistent defense of group rights or exemptions that is based on liberal premises has to ensure that at least one individual right — the right to exit one's group of origin - trumps any group right ... Not to be able to leave the group in which one has been raised for an alternative mode of life is a serious violation of the kind of freedom that is basic to liberalism." 4

Defending a more minimalist view, diversity liberalism prefers the protection of culture over the protection of certain rights of individuals within cultures, maintaining that "liberalism is about the protection of diversity, not the valorization of choice." 5 William Galston, convincingly arguing for the importance of diversity, thus rejects a variety of interventions including autonomy facilitation through education (a topic I critically discuss in detail below), as this newly acquired autonomy might spill over to individuals' personal lives and undermine their capability to "live their lives in ways that express their deepest beliefs about what gives meaning or value to life."

While my argument is developed on the foundations of the diversity liberalism enunciated by Galston and SpinnerHalev (among others), it amends this vision by arguing that the protection of minimalist exit rights (requiring as little or less intervention than diversity liberals typically foresee) ought to be supplemented by more extensive policies promoting what I call "entrance paths."7 Beyond their significant differences, both liberal views — autonomy liberalism and diversity liberalism — share a commitment to exit. Galston maintains that "enforcement of basic rights of citizenship and of exit rights, suitably understood, will usually suffice" for the purpose of enforcing basic liberties. ${ }^{8}$ Jeff Spinner-Halev, despite his convincing claim that "internal and external restrictions are necessary for a community to retain its identity" "and his subsequent support for accommodating restrictive (or "non-reflective") communities, maintains that the conditions of independence must be safeguarded, as they ensure "that no one in the community is coerced. In sum, there must be a real right of exit." 10

I argue that in their minimalist form, exit rights offer little more than lip service, stating that all must be able to exit but providing little detail about how this exit is to be realized and little support for its realization. The lost boys who left FLDS voluntarily exercised their exit rights with mixed results, and the process of disentangling their lives from their earlier affiliation was long and painful, with many of them experiencing disengagement, substance abuse, unemployment, and other difficulties. The inclination and capacity of other boys to exit may be diminished by the experiences of their peers. In these ways exit rights may, in practice, sometimes be counterproductive to the very freedoms they purport to advance.

Further, in their more robust form, exit rights are construed to require interventions that may threaten core values of some cultural sub-groups, as well as some principles of liberal democracy, and thus may not provide true accommodation of cultural difference. Such was the removal of women and children from the FLDS compound, which presented a crude intervention into a comprehensive group in an effort to ensure the protection of human rights (freedom from abuse) and the rule of law (preventing rape and forced underage marriage), but also to ensure the ability of vulnerable members to exit their group if they so choose. While this is an extreme case, the challenge it presents to the discussion of exit is significant and extends to other cultures and other forms of intervention as well, as I will aim to show. A less striking and more common form of unjustified intervention is the focus on autonomy-facilitating education in public schools. I suggest that less interventionist policies, promoting entrance paths, should augment diversity-focused, narrowly construed exit rights as a democratic response to the challenge of cultural diversity. ${ }^{11}$ Policies and social structures that offer entrance paths, like those afforded to (documented) immigrants, can provide opportunities similar to those of substantial exit rights, without the moral burden and some of the adverse political consequences that interventions related to robust exit rights entail. $A$ narrow version of exit rights combined with a strong focus on entrance would thus support a productive response to the needs of members of comprehensive communities, while minimizing the necessity to trespass the boundaries of these communities to protect their members. After establishing the meaning and role of entrance paths, I apply this concept to the educational dimensions of accommodating cultures. Specifically, I consider the role of public schools in preparing future citizens and the complications this raises for liberal democrats. Weighing the arguments for diversity and for choice in the context of schooling strengthens my (diversity-based) argument for entrance paths, and particularly supports a focus on adults rather than on children as the relevant constituency for exit/entrance policies. The consideration of the role of schools in a liberal democracy further justifies prioritizing entrance into dominant society over interventions into sub-cultures.

\section{Comprehensive Communities in Liberal Democracies}

For the purpose of the current discussion, I follow a fairly non-controversial description of culture offered in the otherwise provocative work of Bikhu Parekh: 
"Culture is a historically created system of meaning and significance or, what comes to the same thing, a system of beliefs and practices in terms of which a group of human beings understand, regulate and structure their individual and collective lives." 12 It is worth noting that this is a broad conception of cultural groups, incorporating both religious and other forms of cultural affiliation.

Comprehensive cultural communities-sometimes referenced in the literature as "encompassing," "societal," or "non-reflective" communities_ 13 are defined here as communities whose laws, institutions, and practices regulate the full range of their members' activities. Some comprehensive groups used here to illustrate the argument are the FLDS, certain Jewish Orthodox communities in the US like the Satmars, and the Amish.

The accommodation of cultural sub-groups challenges liberal democracies to closely consider their value systems and their democratic practices. A common assumption is that liberal democratic ideals are threatened by a broad range of comprehensive communities. How should a liberal democratic polity respond to comprehensive, sometimes non-reflective or non-liberal value sets endorsed by some of its members? ${ }^{14}$ Should these be discouraged, or would such a response undermine the very cause of liberal democracies? And if they are tolerated, will that not create a danger in the form of sub-groups within the citizenry which reject and possibly actively oppose basic tenets of society? Moreover, how will the rights of individuals within these communities be protected? These are some of the originating questions for heated scholarly, judicial, and social debates. The responses to these questions are often based on prioritizing either diversity or autonomy, and thus range from demands for institutional support for all cultures, to calls for Socratic education as a means to developing autonomy (and thus rejecting non-reflective views) in all children. ${ }^{15}$

The focus of much current discussion is the question of how much protection do members of comprehensive communities need and what forms should this protection take. The case in defense of comprehensive communities and against crude intervention in their practices has been made by numerous authors committed to diversity ${ }^{16}$ who have broadly argued that the threat posed by these communities to their members and to the dominant society is not as grave as some liberals presume. Devoutly religious communities and other comprehensive groups, these authors broadly argue, can still participate in many of the public practices expected of citizens, and allow their members degrees of freedom sufficient for the purpose of civic equality. On the other hand, liberal democratic theorists committed to autonomy as a basic ideal often advocate for greater intervention in comprehensive cultural groups so as to ensure the protection of vulnerable members, especially women and children. The discussion of children often quickly turns to education and the presumed obli- gation of the state to facilitate the development of their autonomy. This obligation may stand in opposition to the state's tolerance of diversity, or to its willingness to protect sub-cultures that do not give precedence to autonomy.

Both gender equality and autonomy-facilitating education seem to align with the liberal claim for freedom and choice for all members of society. At the same time they seem to threaten some cultural traditions and the prospect of cultural autonomy by intervening in traditional relations among members of cultural groups-as highlighted in the case of the FLDS intervention with which I began. Typically, the way out of this theoretical impasse provided by both autonomy liberals and diversity liberals is a strong justification of the priority of exit rights.

\section{Exit Rights}

Many liberal theorists accept that cultural affiliation plays a significant role in shaping individuals' personal makeup and influencing their choices. As K. Anthony Appiah puts it, "we make choices, but we do not determine the options among which we choose." 17 Theorists of culture and cultural identity vary widely in their understanding of the ways in which culture generates the horizons of choice, and in their subsequent normative conceptions of how democracies should respond to cultures. Most theorists, however, agree on one point-the preeminent importance of the right to exit. ${ }^{18}$ Many insist that exit rights provide a key way of ensuring that all individuals have an opportunity to exercise their autonomy.

The concept of exit rights starts with the notion of the individual as a member of a group, and maintains a concept of the individual as an author of her own fate. It focuses on the practical possibility of a rift between one's own preferences, beliefs, or rights, and the preferences, beliefs, or rights of one's group. Assuming the primacy of the individual over her group leads to prescribing exit rights as a just solution, which is often discussed in relation to the position of women in traditional comprehensive communities. Autonomy liberals suggest changes in traditional property practices that would equalize women's standing within their communities and support their capacity to exit, as well as changes to marriage customs and other traditions. ${ }^{19}$ In addition, for advocates of substantive exit rights, the education of children-including girls of course-is a key way for realizing these rights.

However, the discussion of exit rights in contemporary theory and policy tends to suffer from one of two shortcomings. On the one hand, it sometimes offers an empty promise, a declarative right that is accompanied by neither clear social and legal requirements nor mechanisms of enforcement. Within the web of rights supported by the liberal democratic state, exit rights stand in tension with other forms of protection and accommodation (similar to many other rights that are often positioned in tenuous 
relations with each other). ${ }^{20}$ By stating that individuals are to be allowed to leave their groups, as many have acknowledged, the state does not provide those wishing to leave with a real opportunity to extract themselves from the cultures in which they live. Lacking money and other resources, such individuals may find themselves trapped in their cultures of origin without a real way out. Recognizing this difficulty, some theorists have moved to demand that comprehensive cultures (including illiberal ones) provide members who wish to exit with the full opportunity to do so with little damage. While, as Jacob Levy states, a culture from which an exit has no cost cannot be considered a culture, ${ }^{21}$ there have been significant theoretical as well as legal attempts to ensure that the cost of exit is lowered, so that it becomes realistically possible. ${ }^{22}$ Such attempts include the redistribution of property and reassignment of property rights, as well as robust demands in the domain of education.

This more robust protection of exit raises the second risk I point to in the debate on exit rights. While more realistic exit rights support individuals in their quest for departure, they stand the risk of intervening in comprehensive communities to the point where such communities have little cultural autonomy left. When realistic exit rights are instituted — such as when children are required to develop their autonomy through education-or when communities are required to change their inheritance and property laws so that all members have the material capacity to exit, traditional ways of life may be at risk. Inasmuch as culture in its diversity is a good that enhances personal well being, realistic exit rights can undermine some individuals' well being (premised on belonging to their culture) for the sake of others' (premised on their capacity to leave that same culture), a tension that generates a significant moral burden for policy makers and theorists alike. Recent discussions have developed a careful analysis of multicultural clash points and their consequences. ${ }^{23}$ Within some of these discussions there is a growing recognition that when exit rights are realized through intervention, their potential as a main tool for accommodating culture becomes dubious. ${ }^{24}$ In these detailed responses to the multicultural and gendered challenges to accommodation and tolerance, the key role of dominant society is still focused on varying levels of intervention in minority cultural groups. The expectation of self-reflection and self-correction on the part of liberal society is minimal. The burden of justification lies entirely on the comprehensive communities.

How should society respond to these conflicting visions about vulnerable members of comprehensive groups? I argue that democratic diversity can be accomplished through augmenting minimal exit rights with the practices that I describe as entrance paths, which address adults rather than children, and which are less interventionist in both family and culture than what substantial exit rights require.
Before turning to discuss entrance paths, I briefly examine the question of the motivation to exit. Through this discussion, I hope to substantiate a realistic view of the individual as both culturally embedded and capable of considering alternative ways of life.

\section{Why Exit?}

Leaving a culture, particularly a comprehensive one, is not a step individuals tend to take lightly. ${ }^{25}$ Appiah's question is appropriate here: "Is an identity group something you can simply resign from?" ${ }^{26}$ What might be the reasons for individuals to aspire to exit a comprehensive group, one that establishes and reflects significant parts of their identity and that provides meaning and structure to various aspects of their lives? While individual motivations are probably as varied in this case as they are in any other human endeavor, the ones most relevant to the exit rights discussion can be divided into two categories:

(1) Attitudinal change: Individuals often wish to leave because they have lost some key element needed to motivate them in maintaining their affiliation. They may have lost their belief in the main tenets of the religion or value system; their sense of affiliation may have been compromised by an awkward experience; or their support of the communal goals may have diminished as a result of rethinking.

(2) A sense of injustice: Individuals sometimes wish to leave a comprehensive group because they feel (often justifiably) that they are discriminated against or oppressed within their group, as a result of some of its key norms. This motivation has often been discussed in the literature, particularly in relation to women and minorities-within-minorities. ${ }^{27}$

Clearly, the two motivations can be mixed, such as when one loses her faith because of her sense that the group is unjust in its treatment of certain members (possibly including herself) or when one is oppressed because she does not present the appropriate levels of commitment to the group's main tenets. And yet the motivations are nonetheless distinct, and present distinct challenges to the liberal democratic state. In the latter case-where individuals experience themselves as oppressed by the group to which they belong, and believe that their rights have been abridged by this group-it would seem reasonable to expect some form of basic state intervention sufficient to adjudicate rights claims and to protect and secure a minimal claim —an individual right of exit. But in the former case, where what is at issue is simply an individual's change of heart rather than a sense of oppression, what is at stake is a matter of individual choice, which does not demand such protection. ${ }^{28}$ Such situations require an assumption of descriptive minimal autonomy available to individuals within society, and subsequently require the state to do 
nothing more than provide those individuals who are not oppressed but who wish to exit of their own volition with readily available paths of entry into society. But whether or not such individuals embark on these paths is entirely up to them. Both cases assume that individuality precedes group identity and transcends it, while at the same time maintaining a respectful view of group affiliation. Yet the challenges they present to society are different, and so should the responses be.

Consider Franky, a former member of FLDS and a lost boy. ${ }^{29}$ During his late teens his belief in the teachings of Warren Jeffs - the sect leader — waned, although he still valued the man himself as a mentor. Franky decided to leave the sect's enclosed compound and look for another way of life at a nearby town, outside his community. As he left, his ties to his family and to the world in which he was raised were for the most part severed, and he left behind much of what was dear to him, and much that he still valued.

While Franky's path carries some strong resemblance to Millian self-authorship, it is unclear why the state should sponsor this process through intervening in his group's practices or ensuring a low price for his exit. In a liberal society many important and consequential personal decisions, like marriage or relocation, are routinely made by individuals on their own. While the right to make such decisions is protected by certain liberties such as the freedom of movement (and regulated by some laws), no state intervention is expected for individuals who fail to develop, or choose not to enter, or decide to exit, spousal relations. Similarly, there is no room for intervention in an attempt to regulate the decision making process of Franky and other individuals who face similar choices, or for those other boys in Franky's situation who choose to stay with FLDS. The state should provide such individuals with some support once they exit, in the form of entrance paths, but this support should not take the form of intervention (of the type that Okin and others call for) in the practices of their group, encouragement to exit or provision of tools and skills to exit, as long as no rights are being violated. Thus, while Franky was probably not given the opportunity by FLDS to develop his autonomy to its fullest, as some autonomy liberals would favor, his circumstances and capacities still allowed him to exit his comprehensive group of his own volition.

But what happens when individual rights are violated within comprehensive groups? Consider Teresa, an FLDS member who at 17 is the mother of a young baby, who apparently was fathered by a relative who is twice her age. ${ }^{30}$ If Teresa wishes to exit, and if her wish is a result of oppression or abuse, clearly the liberal-democratic state is required to support the exit attempt in order to prevent or end the infringement of Teresa's rights. If the discussion of supports for exit is limited to such cases, there is little need to extend them beyond existing legal and related mechanisms to protect the rights of all individuals in a democracy. Minimal exit rights which protect the rights of individuals are all that would be required. If the regulations of sexual consent (or statutory rape) and the legal age for marriage were violated, the state can and should respond. It should do so in any cultural context, as there is no justification to exempt groups from legal regulations that are meant to protect the basic rights of individuals, and thus the existing legal mechanisms should suffice to support Teresa.

But many scholarly arguments go much further. ${ }^{31}$ They suggest that in order to facilitate escape from these circumstances, the state must require that Franky and Teresa be educated to know their rights and opportunities, and also ensure that they are able to own property-an unacceptable idea to some groups-so that they do not have economic disincentives to leaving. ${ }^{32}$ However, requirements such as those- to educate all children or to redistribute resources within the group-go too far. They fail to strike a balance between accommodating cultural traditions (that contribute to individuals' sense of belonging and well being) and protecting individuals from harmful circumstances within these cultures, opting for more protection at the price of less accommodation. Supporting Teresa through instituting narrow exit rights is a clear requirement of a state that endorses human rights as part of its basic structure. Beyond that, entrance paths should provide an appropriate response to many of Teresa's and Franky's needs in ways that avoid the political and moral costs of substantial educational or economic intervention.

In the following section I elaborate on the concept of entrance paths for exiting members (acting on either motivation) of comprehensive groups, which should augment the minimal form of exit rights that protect against gross human rights violations.

\section{Entrance Paths}

A vision of democracy that prioritizes diversity as a way to support individual flourishing should be committed to supporting individual members of comprehensive groups not only through minimally protecting exit but also by creating gateways for individuals who prefer ways of life other than the ones in which they were raised. While entrance is in many ways simply the other side of exit, it is often taken for granted in scholarly discussions of exit rights. This neglect often minimizes the significant obstacles and costs to entry presented by mainstream society itself. ${ }^{33}$ Learning new ways of being, acquiring new skills, social ties and capital, sometimes a new language-all these have material and existential costs that must be considered in creating a full account of exit. Exit rights may provide an opportunity to abandon oppressive conditions and exchange them with a way of life that offers more personal freedom. But they offer little direction for navigating this freedom or benefitting from it. 
Liberal theorists tend to assume that freedom is its own reward, and that leaving behind an illiberal way of life provides in itself an opportunity to thrive. This view meshes well with a vision of dominant society as comprised of individuals who freely and consensually exchange positions, views and property with each other. In a liberal democratic society that affords exit rights for all, members of comprehensive groups are free to leave their groups and join others, or leave their groups and live as members-at-large of the society of individuals. But moving from one group to the next does not make one a regular member of the group they have entered, even when the new group is as loosely organized as liberal democratic society seems. A person's upbringing and their original affiliation stays with them in many ways. Some of these ways relate to physical appearance, especially when group affiliation is based on race or ethnicity. Others are more cultural, as signified by the prefix "former" that is often attached to self-identifications. Communities of ex-members, such as ex-Mormons and ex-Amish, often maintain some of the cultural or religious practices and commitments they had in their group of origin, albeit in an amended form; these often serve important social, cultural and religious purposes for their members, and they can indeed facilitate certain forms of entrance for them. ${ }^{34}$ And it is not only that such individuals see themselves as partially defined by their earlier affiliation. Just as important, members of the broader society often see them this way as well. Entrance into mainstream society, then, is no simple matter.

What do entrance paths require? How should they be organized, and what institutional forms might they take? Entrance paths that provide opportunity for engagement in civic life, work, and leisure within dominant society can support the transition of ex-members without requiring them to relinquish their ties to the community of origin. Chandran Kukathas puts it this way: "The most important condition which makes possible a substantive freedom to exit a community is the existence of a wider society that is open to individuals wishing to leave their local groups." 35 But the mere existence of an open society, I suggest, is not enough. Active engagement with entering members is a necessary condition for many who take the step, or enter the process, of exiting a comprehensive group. This active engagement can be both legal and social. Legally, it can occur through the endorsement of laws like the Utah Emancipation Statute (and similar laws enacted in 13 states) ${ }^{36}$ that allow runaway and homeless minors, under certain circumstances, to be recognized as legally autonomous and thus support their entrance into society. When older teenagers like Franky choose to exit their comprehensive group, the absence of legal guardianship can impede their capacity to gain employment, receive medical care, and in other ways become members of society. Emancipation statutes recognize this unique legal circumstance, and provide an entrance path in the form of legal autonomy. In some cases access to the judiciary is itself an entrance path into the mainstream society, particularly when individuals are pressing claims for basic rights, either against former associates or against individuals in the broader society who may take advantage of their vulnerability.

Such gateways of entry for exiting individuals should also include social dimensions. For example, institutions of higher learning like community colleges should be encouraged to actively seek ex-members by developing institutional ties with organizations of ex-members, thus providing them with opportunities to gain skills and ties necessary for equal membership in society. Likewise, the state can support (through providing tax-exempt status or other benefits) organizations of former members of subgroups, which are often the best entrance ports into dominant society for exiting individuals. Such organizations provide many forms of emotional, informational, educational, legal, and financial solidarity and support. Individuals in the midst of transition into the broader society can indeed be likened to immigrants, even if they did not move from across a national border. Such individuals have special needs, and there is no reason why a liberal state ought not to attend to these needs through public policy. In the case of Yoder v. Wisconsin, for example, ${ }^{37}$ which granted the Amish exemption from the last two years of compulsory education for their children, focusing on an entrance path would have allowed the state of Wisconsin to also establish a fund to support adult education for drop-outs, including Amish, who later in life struggle to enter the workforce. Such measures do more than provide educational and economic opportunities; they enhance the possibility of entrance to the larger society for individuals wishing to choose this path.

Other existing structures-some public, some privatethat are aimed at supporting immigrants can be used (or replicated) to support this form of internal migration. Such responses would include culturally sensitive provision of services to the health needs of those who are exiting traditional societies; support in navigating the housing market and financial institutions; and other related forms of assistance that can sometimes be found in "immigrant clinics." ${ }^{38}$ Spinner-Halev acknowledges the need for such support and its practical implications: "To enable people to leave by easing the transition to the outside world, the Hutterites [but not the Amish or Ultra orthodox because they can own property and save money] should set aside a small fund for members who leave their community. . . . No one should become wealthy by leaving, but a few thousand dollars would help members leave the community if they wish." ${ }^{39}$ While he accurately identifies the need for material support, Spinner-Halev misplaces the responsibility for providing it. The dominant society and its formal institutions should provide support for new members rather than burdening comprehensive groups 
through intervention and regulation. To illustrate using Spinner-Halev's example, the fund to support exiting Hutterites should be a public fund rather than a governmentrequired Hutterite fund. The Hutterites are paying the price of exit by losing members, giving up attachments, and weakening their already marginal group. The dominant society is gaining new members as well as further support for its already triumphing value set. Thus, it can afford, and should be expected to pay (materially and otherwise), for this benefit.

The institution of entrance paths is critical to making a change of one's cultural affiliation a realistic possibility, regardless of the motivation for doing this.

This change of focus - from sub-groups and exit to dominant society and entrance-is justified for a number of reasons. First, if exit is understood as promoting autonomy or choice, and if those are valued by the dominant society but not by comprehensive communities, then the burden of realizing these values should fall on the dominant society. Realizing these values provides dominant society with ethical and expressive benefits. Shachar argues that the burden of exit should not fall on individuals' shoulders:

The "right of exit" solution ... throws upon the already beleaguered individual the responsibility to either miraculously transform the legal-institutional conditions that keep her vulnerable or to find the resources to leave her whole world behind. Surely it is troubling when a solution demands that those who are the most vulnerable must pay the highest price, while the abusers remain undisturbed. ${ }^{40}$

A similar argument should hold for burdens placed on comprehensive groups who may be marginalized or discriminated against, partly because they reject the values of choice and autonomy (or do not give them a central role in their belief systems). Since the possibility of exit for their members makes these groups more vulnerable or undermines some of their goals, the cost of exit should not be born solely by these groups, as it is when exit is ensured through intervention in their practices. Sarah Song recognizes the importance of shifting the focus of intervention when she notes that "critique of minority norms and practices ... can divert attention from the majority culture's own inequalities, shielding them from criticism and perhaps even fueling discourses of superiority within the dominant culture." ${ }^{\circ 1}$ For her this shift demands a reconsideration of patriarchal and other unequal practices within dominant culture. While this is an important cause, the same premise justifies generating gateways for exiting members to create new affiliations within the dominant society.

Some may argue that comprehensive groups should bear the burden of exit, because the costs have been generated by their illiberal ways. ${ }^{42}$ This suggestion rests on a view of the dominant society as a free and open realm, into which foreign elements enter carrying with them illiberal, possibly dangerous ideas and ways of life. The alternative view, which I share with Kymlicka, Appiah, Galston, and other diversity liberals, is that society is better described as a loose collection of individuals_-some of who enjoy multiple affiliations - and groups - some of which are more comprehensive than others. Under this description, there is no reason to depict comprehensive groups as foreign elements that introduce complications into an otherwise harmonious dominant society. The cost of crossing the lines between groups is not generated by comprehensive groups, but rather by the priority given to boundary crossing and freedom of movement by the liberal values of the dominant society. It is thus only fair that the liberal state should defray the cost of entrance paths for individuals wishing to join the dominant society.

Second, focusing on entrance is justified since it expresses an acknowledgment of the importance of cultural belonging for individual well-being, while still retaining a view of the individual as transcending her cultural group. By limiting interventions of the liberal state in the affairs of comprehensive communities, it allows cultural groups maximum freedom to maintain their traditional ways of life, while at the same time respecting and supporting individuals who choose to leave.

Moreover, the focus on entrance rather than on exit alone allows the discussion to focus on adults (including older teens) rather than on children as the relevant constituency. The discussion of cultural accommodation and choice has long been mired in the debate over parental rights and family prerogatives. While the debate on children's and parents' rights falls beyond the purview of my argument here, it should be noted that the focus on adults offers a less controversial argument for cultural accommodation, one that would not be viewed as infringing on parents' right to raise their children as they see fit.

As I've already mentioned, many autonomy liberals have argued that effective exit rights require that the state, through the system of public education, introduce all children to a comprehensive liberal pedagogy centered on the importance of individual autonomy and voluntary association and hence on the right of all adult citizens to exit their groups of origin. As I argue below, many of these education-centered arguments are misplaced. A focus on the availability of entrance paths for adults who wish to exit rather than on teaching children that they should consider exit provides a morally and politically more viable solution to the problem of exit.

\section{Exit and Entrance Through Schools}

For many liberal democrats, public schooling is a natural arena in which to address challenges of cultural accommodation and integration: since children are already compelled to attend school, promoting liberal values there would not involve any additional intrusion into the private and cultural sphere. While the social effects of this 
exposure may still be controversial, particularly because of its possible "spillover effect," 43 it is often assumed that for individuals to become effective choosers they must develop a familiarity with the diversity of values and acquire the skills to navigate them at an early age.

Is it justified for publicly-funded schools (including private schools enjoying tax exemptions and other benefits) to teach children about their opportunities to exit their cultures of origin? Despite concerns about parental rights, some theorists answer in the affirmative, claiming that in fact this is one of the main charges of schools as public institutions. Exposing children to other cultures is justified as a way to generate tolerance, a key aspect of democratic society, but also as a way to facilitate autonomy and develop critical capacities in children. ${ }^{44}$ These are sometimes used as key justifications for publicly funding schools. In Michael Hand's terms, ${ }^{45}$ schools are charged with developing dispositional autonomy in children (or the inclination to determine one's own actions), and this mandate is crucial for advancing their circumstantial autonomy (or the condition of being free to determine one's own actions). In other words, if children learn to be autonomous, they may well reject cultural and religious contexts in which they are not free to exercise this autonomy, thus endorsing free society over more limiting cultural contexts.

Schooling practices that provide the foundations for substantial exit rights are commonly based on a "great sphere" understanding of the school as a vehicle for the integration of children from many cultures into one institution, where they learn to understand, tolerate, and respect each other. They are taught to see value in ways of life other than their own, and develop an autonomous vision of the life they wish to lead. In Callan's view this is a safeguard against children's servility and against allowing parents to extend their rights into the realm of their children's freedom. ${ }^{46}$

Schools as great spheres are thought to protect individual rights and civic equality, while at the same time introducing the main tenets of a liberal society by teaching children to endorse liberal democratic views. Schooling carries the potential to liberate individuals from oppressive cultures where their rights are trampled, for example by exposing women and girls from traditional cultural groups to visions of gender equality; at the same time this approach presumably supports the possibility of effecting change in these cultures by introducing their members to other, more desirable ways of thinking that are based on civic equality and non-discrimination.

The relationship between this liberal democratic argument about education and the liberal emphasis on exit rights is clear: For exit rights to do what they are meant to do, they must be made available to all members of all cultural groups within society, who must become aware of them, and be able to appreciate and exercise them. For this to happen, a number of interventions by the state into comprehensive cultural groups would be required, first and foremost in the form of public education for all members. This education must familiarize all members with alternative ways of life and teach everyone how to argue for and how to access them. All members must possess the skills and knowledge necessary for surviving exit, should they choose it. Diverse schools and pedagogical practices are assumed to provide children with desirable opportunities to consider the set of values parents and communities aim to instill in them, thereby giving them a chance to decide for themselves about their own conception of the good as they move forward in their lives as free individuals.

This line of argument, I suggest, goes too far in the direction of intervention, and should not be endorsed by liberal democrats who are committed to cultural diversity and tolerance. Public education should not be considered a key part of the response to the cultural accommodation challenge, as it goes well beyond the protection of human rights. In addition, at least under current conditions in the US, public schools cannot effectively respond to this charge because families who oppose such teachings have the choice to opt out.

Consider, for example, the traditional education of Orthodox Jewish girls, which requires them to be shielded from what are perceived to be the corrupting influences of non-Orthodox society, and to learn only what is necessary for fulfilling their future roles as Jewish home makers. The autonomy-liberal approach to exit rights would necessitate a significantly different education. ${ }^{47}$ These girls would have to be exposed to other ways of life, and learn to question their own, thus corrupting their belief system and their purity in the eyes of their religious leaders and some of their fellow members. To offer them substantial exit rights, as advocated by autonomy-liberals, they must learn "general education" curricula, such as math and English (particularly in communities that function in languages that are not useful for individuals who choose to exit, such as Yiddish). Rather than attending schools that serve only Orthodox girls, they may be required to sit in the same classroom with boys and with members of other cultures, as advocates of the "great sphere" demand. It is unlikely that the community leaders would endorse this kind of education for girls, which would be regarded as threatening both to the perceived purity of the girls and the prerogatives of a rabbinically-centered community. If some girls or their families would choose such an education, this might in itself indicate a form of exit, creating a difference and a distance between themselves and the rest of the community. The girls may consequently be deemed undesirable for marriage, which is a damning label in a closed, traditional community. The leaders and the parents of these girls may reasonably oppose this kind of education, as Shelley Burtt has asserted, because "what we see as intolerance of differing views of the world 
is, from this perspective, fear of the corruption of faith." 48 As Song suggests, this may also generate a reactionary response, rendering girls more vulnerable in their communities, in addition to masking inequalities in dominant society.

Thus, contrary to widespread assumptions, education for autonomy may carry devastating consequences for individuals and families who belong to comprehensive communities, and may significantly undermine the project of cultural accommodation. Beyond these undesirable consequences for individuals and for the moral standing of the state whose acts may promote perverse consequences, this form of education is not demanded by liberal democratic values. Granted, the Jewish Orthodox girls may not be given the full set of opportunities to develop certain dimensions of their lives. They may face a narrow field of professional opportunities, and they may have other, significant restrictions on their freedom of choice. But their condition does not amount to a violation of human rights, and does not require for the state to step in and protect them. Belonging to a cultural group or espousing a set of norms necessarily entails some limitation of opportunities, which is the price an individual pays for participating in a shared moral context. Some contexts are more comprehensive than others, and some seem to outsiders to be more limiting. But inasmuch as they do not violate laws that are meant to protect individual rights or cause harm to bodily integrity and the like, they do not amount to a cause for intervention. Therefore, mandating autonomyfacilitating education for individuals within these cultures as a way to protect individuals from their effects is unjustified.

Moreover, such an education policy is unlikely to deliver the substantive exit rights it aspires to offer, for it is likely simply to encourage traditionalist parents to send their children to private schools or to home school them, in both cases placing them beyond the reach of liberal public education. Politically speaking, a hard core emphasis on the an autonomy-centered system of education stands the risk of alienating from mainstream society and its institutions (including public schools) any and all members of those cultures who believe that their set of values is indeed reflective of the truth. Devout religious sects would likely be suspicious of institutions that aim to support their children in a journey outside their belief system.

In this sense education for autonomy and "great sphere" education in the public schools cannot satisfy the demands of cultural accommodation or those of liberalism. While schools are indeed charged with widening students' horizons, directing much of these efforts towards one's culture or religion seems to miss the point. In this context, choice should not be construed as the opportunity to abandon your way of life for another. As long as children are able to participate as civic equals - a requirement that should be understood as a matter of knowledge, skills, and habits taught, rather than as a matter of soul-craft- their affiliations are beyond the realm of justified public (including educational) intervention.

The argument against providing the conditions for exit rights through schooling thus becomes, in essence, a diversity-based argument against autonomy-facilitating education. While this is by no means an argument against schools' role in teaching citizenship, this requirement should not directly conflict with the expectations of religious parents in comprehensive communities. ${ }^{49}$ This view of cultural accommodation does not require autonomy facilitation or exposure to alternative ways of life; it does not seek to encourage all individuals within society to become autonomous authors of their lives. Instead of focusing on socializing the young, it centers on opening paths of entry to those who wish to exit their communities as independent individuals_ as adults or as older adolescents.

Such entrance paths should focus on those who already wish to exit, and offer opportunities to new or aspiring members of the dominant society. As argued above, programs such as adult education stand a better chance of facilitating the voluntary movement of individuals into the broader society than do more interventionist-and threatening — approaches. Franky, like other lost boys, fell into substance abuse when he left FLDS. He had no connections, no training, and no clear way to acquire those. Opportunities for adult education and job training, as well as opportunities to participate in civic and communal life, could have assisted him in the transition. His key needs were related not so much to exit as to entry. As a new member of the dominant society he could be assisted through professional development and work preparation courses, through support to relevant civic organizations, and through the recognition of his journey by dominant society through the other legal and social means that constitute entrance paths.

These entrance paths are meant to welcome new members, accepting their decision to exchange one cultural affiliation with another, and supporting them in the process of becoming members-at-large of a liberal democracy. Such policies are not meant to encourage exit, but rather to indicate dominant society's willingness to support those who wish to exit, and to share the burden of their decision. The absence of entrance paths can be a strong deterrent to exit, possibly as formidable as the original community's efforts to keep its members in. If a liberal democracy aims to express support for the idea that all individuals should be allowed to change their cultural affiliations or otherwise express their status as authors of their lives, it should start by providing support to those who would like to join its loosely organized public space. Such support makes sense on both moral and pragmatic grounds, as liberals who are serious about freedom of choice ought to recognize. 


\section{Conclusion-Bearing the Burden of Exit}

The state enforcement of exit rights is a form of intervention espoused by liberal democrats as a way to sustain a commitment to individualism while accommodating cultural groups. I have argued that the literature on this matter has been skewed in its support for more intervention and state coercion than is pragmatically required, politically productive, or morally justified. To correct that, narrow exit rights that protect basic human rights should be augmented with policies and state actions that promote entrance paths, which do not carry the moral or pragmatic costs of intervention but provide similar (and indeed preferable) advantages.

Exit, as an expression of personal choice, is a key aspect of contemporary liberal democratic approaches to accommodating minority cultures, particularly comprehensive ones. Positioning exit as a key right for members of minority groups seems to allow liberal democrats to maintain their endorsement of diversity while preserving their commitment to individual rights and freedoms. Consequently, the burden of realizing these values should first and foremost be assigned to the dominant society and to the liberal democratic state that "represents" it.

Moreover, instead of robustly promoting exit rights, through autonomy-facilitating education and other forms of intervention in communal practices, liberals should open entrance paths while accommodating a wide range of established conceptions of the good, and focus these policies on adults rather than on children. Easing the transition from comprehensive communities to dominant society would mean taking responsibility for providing gateways and support in adjustment. Protecting Teresa from abuse and forced marriage is a key function of a liberal democratic state, covered by existing laws regarding sexual conduct and consent, and the regulation of marriage. The state must protect her rights while allowing her to either stay in her culture or to leave. But it is not obliged to encourage her to leave. If she leaves, it should be of her own volition. And in that event, she should expect to encounter a range of practices, institutions, and structured opportunities designed to facilitate her entrance into the dominant society, if not positively to welcome her there.

\section{Notes}

1 See Simon and Townsend 2007.

2 See Blumenthal 2008. See a discussion of the legal history of the case, including earlier charges against Jeffs involving being an accomplice to child rape and officiating underage marriage in Cluck 2008. This article offers an argument for targeting the law so that it allows for prosecuting actions like Jeff's while protecting other marriage officiants who preside over the marriage of underage girls.

3 Appiah 1994; Burtt 1994; Galston 2002, 2005; Kroeker and Norris 2007; Kukathas 1992; Macedo 2000; Okin 2002; Phillips 2007; Shachar 2001;

Song 2007; Spinner-Halev 2000.

4 Okin 2002, 205-6.

5 Galston 1995, 523.

6 Galston 2002, 28.

7 I do not pursue here two other objections I have to the common portrayal of exit in liberal theories.

First, I find the description of dominant society and the enclaves it encompasses empirically inaccurate and theoretically unproductive; second, it seems unhelpful to think about exit (and other significant choices individuals make) as one step rather than an ongoing process. In this paper I focus on the role of exit rights in preserving freedom. I take up some of the other objections in Ben-Porath 2010.

8 Galston 2005, 41.

9 Spinner-Halev 2000, 70.

10 Ibid, 71.

11 This line of argument aligns with David Plotke's 2006 account of political incorporation as a preferable response to anti-democratic political communities in a democracy over toleration and repression. There are some differences in our views that I cannot explore here, mostly related to the fact that Plotke focuses on political responses while I put here more emphasis on social structure.

12 Parekh 2006, 143.

13 Shachar 2001; Spinner-Halev 2000. Also see Kymlicka 1995, 75: “'societal culture,' whose practices and institutions cover the full range of human activities, encompassing both public and private life."

14 I consider comprehensive groups to be ones that "share a comprehensive world view that extends to creating a law for the community." Shachar 2001, 2.

15 Spinner-Halev 2000 argues for liberal accommodation of restrictive communities. Shachar 2001 calls for tolerance and respect for deep cultural disagreements, which still requires exit rights; Macedo 2000 makes the case for intervening in restrictive communities to support the main values of the liberal democracy within which they live; see also Eisenberg 2003, Galston 1995, and McLeod 2003.

16 Burtt 1994; Galston 2002; Kroeker and Norris 2007; Kukathas 1992; Phillips 2007; Spinner-Halev 2000.

17 Appiah 1994, 155.

18 Galston 2002; Kukathas 1998; Kymlicka 1995; Okin 2002.

19 Okin 2002.

20 Dworkin 1978; Williams 1982.

21 Levy 2000, 112. 
22 See the discussion of Muslim communities in France in Bowen 2009; an effort by the Canadian government to offer clear guidelines for reasonable accommodation, Bouchard and Taylor 2008.

23 Shachar 2001; Song 2007.

24 See for example Mazie 2005.

25 I am leaving aside for the purpose of the current argument the possibility of immigration as a form of exit, because it offers a very different horizon, and also creates different practical and ethical challenges to the 'existing' individual. See Callan 2005.

26 Appiah 2005, 78. Appiah goes on to investigate the weaknesses and strengths of exit rights as a mechanism for protecting individuals. Loyal to his commitment to individual autonomy understood through a complex lens of personal and social psychology, he asserts that it is possible to maintain state neutrality in the treatment of different groups by treating "people of diverse social identities with equal respect" (91).

27 See Eisenberg and Spinner-Halev 2005. See a discussion on the Amish and their motivations to exitdistancing from the faith, and a sense of oppression (sometimes intertwined), including surveys of ex-Amish in Hurst and McConnell 2010; a host of personal stories, many of which relate to these two categorizations (and some to other personal matters, including domestic abuse) in the ex-Mormon community in http://www.exmormon.org/stories.htm; on ex-Haredim (or members of the Jewish Orthodox community) see Winston 2005, where he also discussed the detrimental effects of the lack of entrance opportunities.

28 Choice is one mechanism among others to realize freedom. Freedom is not satisfied by choice, and other social mechanisms can protect freedoms. I discuss these matters in Ben-Porath 2010.

29 See Franky's story in Simon and Townsend 2007, as well as a related story on two young men, Caleb and Frankie, in Doane 2008. See a legal discussion, including an argument in support of Utah's Emancipation of Minor act that allows certain youths to be recognized as legally autonomous (an act that amounts to a basic entrance path) in Wharton 2007.

30 The description of Teresa is based on her story as described in Blumenthal 2008. The women who are still sect members refused to divulge the identity of their children's fathers out of fear of aiding the legal measures against men in the sect. The lives of FLDS women and girls were the subject of numerous news reports and books. On the restricted life of girls and women under Warren Jeffs' rule see Jessop and Brown 2009. Current sect members, including women, object to the negative description of their lives by former members and by the authorities in Texas and Arizona. Jeffs was handed a lengthy prison sentence as an accomplice to rape because of his role in arranging the marriage of a 14-year-old girl to an older man (with her parents' blessing). He was also charged with raping a young boy and with other similar crimes.

31 On education, see Brighouse 1998, Callan 1997, Reich 2002; on redistribution see Spinner-Halev 2000.

32 This is not to claim that property rights are not central to liberal democratic visions. Rather it is to suggest that inasmuch as the state does not intervene when a family's assets are concentrated in the hands-or bank account - of one family member, for example the husband, it should similarly not intervene in the property allocation practices of comprehensive groups. And inasmuch as the state intervenes when issues of distribution arise in the case of divorce-a form of exit-so too it can intervene on behalf of exiting members. However, exit from cultural groups raises some different issues from the case of divorce, particularly because the basic unit - the group — does not disintegrate as a result of individual members' exit. The demand to avoid excessive intervention, that justified non-intervention in the allocation of material goods, still stands post-exit, whereas post-divorce it does not.

33 Kukathas 1992 is a notable exception.

34 On the challenges ex-members face, see Hurst and McConnell 2010 on ex-Amish; Winston 2005 on ex-Orthodox; Jessop and Brown 2009 on ex-FLDS.

35 Kukathas 1992, 134.

36 See Wharton 2007.

37 Wisconsin v. Yoder, 406 U.S. 205 (1972). The United States Supreme Court decided in this landmark case that Amish children should be exempt from compulsory education after the eigth grade in order to protect their parents' right to freedom of religion.

38 On legal clinics and how they empower as well as help integrate immigrants into their new homeland, see Cruz 2004; on medical attention that is culturally sensitive and responds to the unique needs of immigrants and specific cultural groups see Walker and Barnett 2007, especially section 1 that sets up the issues of culturally responsive medicine. The legal, medical, educational, and social needs of immigrants are widely recognized and sporadically responded to in mainstream American society. Because the needs of internal immigrants - or exiting members-are often similar, and clearly the need for culturally sensitive delivery of these services is similar, the lessons of immigrant services can be learned for the purpose of developing related entrance paths for exiting members of comprehensive groups. 
39 Spinner-Halev 2000, 77.

40 Shachar 2001, 43-44.

41 Song 2007, 142.

42 I thank a reviewer for raising this point.

43 Tomasi 2001.

44 Ackerman 1981; Callan 1997; Brighouse 1998.

45 Hand 2006.

46 Callan 1997, 221-232.

47 Note that some parts of the Ultra Orthodox society in Israel today are becoming more open to the education of girls and women, as long as this education (including higher and professional education) is pursued in institutions that serve mostly or only members of this community. See discussion of this group that includes an argument for greater protection and accommodation in Margalit and Halbertal 1994.

48 Burtt 1994, 64.

49 I cannot develop here the constructive view of citizenship education that would allow for such accommodation. Broadly, I have in mind an education that is based on a conception of citizenship as shared fate. I discuss this in more detail in Ben-Porath 2006; as well as in forthcoming work.

\section{References}

Ackerman, Bruce. 1981. Social Justice in the Liberal State. New Haven, Connecticut: Yale University Press. Appiah, Kwame Anthony. 1994. "Identity, Authenticity, Survival: Multicultural Societies and Social Reproduction." In Multiculturalism: Examining the Politics of Recognition, ed. Amy Gutmann. Princeton, NJ: Princeton University Press.

- 2005. The Ethics of Identity. Princeton, NJ: Princeton University Press.

Ben-Porath, Sigal. 2006. Citizenship under Fire: Democratic Education in Times of Conflict. Princeton, NJ: Princeton University Press.

Ben-Porath, Sigal. 2010. Tough Choices: Structured Paternalism and the Landscape of Choice. Princeton, NJ: Princeton University Press.

Blumenthal, Ralph. 2008. "52 Girls are Taken from Polygamist Sect's Ranch in Texas.: New York Times, April 5 (http://www.nytimes.com/2008/04/05/us/ 05jeffs.html) accessed October 14, 2009.

Bouchard, G., and C. Taylor. 2008. Building the Future: A Time for Reconciliation. Quebec: Commission de Consultation sur les Pratiques d'Accommodement reliées aux Différences Culturelles.

Bowen, J.R. 2009. Can Islam Be French? Pluralism and Pragmatism in a Secularist State. Princeton, NJ: Princeton University Press.

Brighouse, Harry. 1998. "Civic Education and Liberal Legitimacy.” Ethics 108: 719-45.
Burtt, Shelly. 1994. "Religious Parents, Secular Schools: A Liberal Defense of an Illiberal Education." Review of Politics 56(1): 51-70.

Callan, Eamonn. 1997. "The Great Sphere: Education against Servility." Journal of Philosophy of Education 31(2): 221-32.

- 2005. "The Ethics of Assimilation." Ethics 115: 471-500.

Cluck, Tessa. 2008. "Avoiding over Prosecution of Marriage Ceremony Officiants: Alternatives to the Warren Jeffs Prosecution.” Loyola Law Review 54: 738-74.

Cruz, Evelyn H. 2004. "Validation through Other Means: How Immigration Clinics Can Give Immigrants a Voice When Bureaucracy Has Left Them Speechless." St. Thomas Law Review 17(3): 811-34.

Doane, Seth. 2008. "Broken Ties." ABC News, May 27. (http://www.cbsnews.com/stories/2008/05/27/ 48hours/main4130162.shtml.) accessed January 22, 2010.

Dworkin, Ronald. 1978. Taking Rights Seriously. Cambridge: Harvard University Press.

Eisenberg, Avigail. 2003. "Diversity and Equality: Three Approaches to Cultural and Sexual Difference." Journal of Political Philosophy 11(1): 41-64.

Eisenberg, Avigail, and Jeff Spinner-Halev, eds. 2005. Minorities within Minorities: Equality, Rights and Diversity. UK: Cambridge University Press.

Galston, William. 1995. "Two Concepts of Liberalism.” Ethics 105(3): 516-34.

- 2002. Liberal Pluralism: The Implications of Value Pluralism for Political Theory and Practice. Cambridge: Cambridge University Press.

- 2005. The Practice of Liberal Pluralism. Cambridge, UK: Cambridge University Press.

Hand, Michael. 2006. "Against Autonomy as an Educational Aim." Oxford Review of Education 32(4): 535-50.

Hurst, Charles E., and David L. McConnell. 2010. An Amish Paradox: Diversity and Change in the World's Largest Amish Community. Baltimore: Johns Hopkins University Press.

Jessop, Flora, and Paul T. Brown. 2009. Church of Lies. (city): Jossey Bass.

Kroeker, Frances, and Stephen Norris. 2007. "An Unwarranted Fear of Religious Schooling." Canadian Journal of Education 30(1): 269-90.

Kukathas, Chandran. 1992. "Are there any Cultural Rights?” Political Theory 20(1): 105-39.

- 1998. "Liberalism and Multiculturalism: The Politics of Indifference." Political Theory 26(5): 686-99.

Kymlicka, Will. 1995. Multicultural Citizenship: A Liberal Theory of Minority Rights. Oxford: Oxford University Press.

Levy, Jacob. 2000. The Multiculturalism of Fear. New York: Oxford University Press. 
Macedo, Stephen. 2000. Diversity and Distrust: Civic Education in a Multicultural Democracy. Cambridge, MA: Harvard University Press.

Margalit, Avishai, and Moshe Halbertal. 1994. "Liberalism and the Right to Culture." Social Research 61(3): 491-510.

Mazie, Steven V. 2005. "Consenting Adults? Amish Rumspringa and the Quandary of Exit in Liberalism." Perspectives on Politics 3(4): 745-59.

McLeod, Colin. 2003. "Shaping Children's Convictions." Theory and Research in Education 1(3): 315-30.

Okin, Susan Moller. 2002. "Mistresses of their own destiny: Group rights, Gender, and Realistic Rights of Exit." Ethics 112: 205-30.

Parekh, Bhikhu. 2006. Rethinking Multiculturalism. Cambridge, MA: Harvard University Press.

Phillips, Anne. 2007. Multiculturalism without Culture. Princeton, NJ and Oxford: Princeton University Press.

Plotke, David. 2006. "Democratic Polities and Antidemocratic Politics." Theoria 53(111): 6-44.

Reich, Rob. 2002. Bridging Liberalism and Multiculturalism in American Education. Chicago: University of Chicago Press.

Reitman, Oonagh. 2005. “On Exit.” In Minorities within Minorities: Equality, Rights and Diversity, ed. Avigail Eisenberg and Jeff Spinner-Halev. UK: Cambridge University Press.

Santa Clara Pueblo v. Martinez, 436 U.S. 49 (1978).

Shachar, Ayelet. 2001. Multicultural Jurisdictions: Cultural Differences and Women's Rights. Cambridge: Cambridge University Press.
2010. "Faith in Law?" Philosophy and Social Criticism 36(3/4), 395-411.

Simon, Dan, and Amanda Townsend. 2007. CNN, September 7 (http://www.cnn.com/2007/US/09/07/ lost.boys/index.html) accessed October 14, 2009.

Song, Sarah. 2007. Justice, Gender and the Politics of Multiculturalism. New York: Cambridge University Press.

Spinner-Halev, Jeff. 2000. Surviving Diversity: Religion and Democratic Citizenship. Baltimore: Johns Hopkins University Press.

Tomasi, John. 2001. Liberalism beyond Justice. Princeton, NJ: Princeton University Press.

Walker, Patricia Frye, and Elizabeth Day Barnett. 2007. Immigrant Medicine, (city): Elsevier.

Wharton, Christopher T. 2007. "Statute Note: Deserted in Deseret: How Utah's Emancipation Statute is Saving Polygamist Runaways and Queer Homeless Youths." Journal of Law and Family Studies 10: 213-21.

Williams, Bernard. 1982. Moral Luck. Cambridge, UK: Cambridge University Press.

Williams, Melissa. 2003. "Citizenship and Identity: Citizenship as Shared Fate and the Functions of Multicultural Education." In Citizenship and Education in Liberal-Democratic Societies, ed. Walter Feinberg and Kevin McDonough. Oxford, UK: Oxford University Press.

Winston, Hella. 2005. Unchosen: The Hidden Lives of Hasidic Rebels. NY: Beacon Press.

Wisconsin v. Yoder, 406 U.S. 205 (1972). 